\title{
Financial Systems Theory and Control of Finances: The Mediating Role of Psychological Empowerment in the Relationship between Transformational Leadership and Employee Engagement: An Evidence from Vietnam
}

\author{
QUANG HUNG DO ${ }^{1}$, ANH TUNG TRAN ${ }^{2}$, TUAN TRAN THE ${ }^{*}$ \\ ${ }^{1}$ Faculty of Information Technology, University of Transport Technology, Hanoi, VIETNAM \\ ${ }^{2}$ School of International Education, Hong Bang International University, Ho Chi Minh City, \\ VIETNAM \\ ${ }^{3}$ Faculty of Transport Economics, University of Transport Technology, Hanoi, VIETNAM
}

\begin{abstract}
Employee engagement has been closely linked to work attitudes (e.g., job satisfaction, intentions to quit, withdrawal), employees' innovation, organizational success and financial performance (e.g., profits, shareholder return) and, therefore, getting much attention from academia and practitioner communities. Additionally, to have a full insight in employees, organizations have to take care of psychological side of employees, which manifests in psychological empowerment. This study investigates the mediating role of psychological empowerment in the relationship between transformational leadership and employee engagement in the context of Vietnam. Data were collected through a survey conducted in Vietnam using 254 respondents who are employees and managers. A researcher-administered questionnaire survey method was used for data collection. The findings reveal that Psychological Empowerment is significantly related with Transformational leadership and Employee Engagement; there is a direct effect of Psychological Empowerment and Employee Engagement; and Transformational leadership not only has a direct impact on Employee Engagement, but also has indirect effect through Psychological Empowerment as a mediating variable. These findings have several implications also for human resource practices in organizations. It is expected that this study provides valuable information to consider in business practice for the development of interventions aimed at mitigating turnover behavior and maximizing organizational performances through an engaged workforce.
\end{abstract}

Key-Words: Financial Systems Theory, Control of Finances, Psychological Empowerment, Transformational Leadership, Employee Engagement.

Received: June 20, 2020. Revised: October 12, 2020, Accepted: November 8, 2020. Published: November 20, 2020.

\section{Introduction}

In the trend of globalization across the countries, organizations have been experiencing tremendous challenges to maintain a competitive advantage on the global front. Today more than ever, the human workforce, and more specifically the ability to attract and retain the knowledge power has become one of the most important factors of organizational success [1, 2]. This holds important implications for organizations that strive to be the best in their markets and to maintain a competitive advantage. They need to outsmart their competition in terms of attracting and retaining their pool of knowledge talent. Accordingly, organizations need to have managers and leaders who can develop enthusiasm and commitment among staffs by using behavioral and personality characteristics such as charisma, the ability of high influence and extended vision which will lead to utilize the total amount of talent and effort behalf of achieving 
organizational goals. Behavioral science researchers have been seeking for appropriate managerial ways to increase the level of employee's commitment and enthusiasm toward working [3]. Such leaders are called transformational leaders. Transformational leaders have the ability to encourage employees toward gaining valuable organizational goals include higher productivity, presenting better services and solving social problems. Transformational leadership theory is a prominent representative of novel theories that have occupied center stage in leadership research in the last three decades [4]. Follower engagement, performance and development are targeted outcome of such leadership [5]. Accumulating evidence showed that transformational leadership is positively associated with work attitudes and behavior at both individual and organization. It is clearly that there is an importance for paying attention to understanding the mechanisms and processes through which transformational leadership influences on work-related attitudes such as employee engagement. Employee engagement is considerable as a strategic approach for driving improvement and encouraging organizational change, which concluded that employee engagement and satisfaction were related to meaningful business outcomes at magnitude that is important to many organizations and that these correlations generalize across companies.Psychological empowerment is a concept originating from industrialorganizational psychology. It is well recognized that empowerment is the opportunity an individual has for autonomy, choice, responsibility, and participation in decision making in organizations. Psychological empowerment refers to an "intrinsic task motivation reflecting a sense of self-control in relation to one's work and an active engagement with one's work role. It was indicated that psychological empowerment has an important role in positive work outcomes [6-8]. A considerable volume of literature on the relationship between transformational leadership and employee engagement has been conducted. however, there is hardly any trace of the mediating role of psychological empowerment in the relationship between transformational leadership and employee engagement, especially in Vietnam's context. Due to a gap in the academic literature on the topic, the objective of this study is to empirically explore the mediating role of psychological empowerment in the relationship between transformational leadership and employee engagement among employees in the Vietnamese organization.

A comprehensive literature study is conducted on the constructs of transformational leadership, employee engagement. The aim is to do a comprehensive literature review in order to develop a conceptual model that reflects the role of psychological empowerment in the relationship between transformational leadership and employee engagement, which, in turn, will provide valuable information on the practices that organizations should focus on to engage and retain their employees. This study also tests this conceptual model and attendant hypotheses. The remainder of this paper is organized as follow. Section 2 is devoted to literature review and hypothesis development. The research methodology is presented in Section 3. Section 4 presents results. Finally, Section 5 gives conclusions and discussions.

\section{Literature Review and Hypothesis Development}

\subsection{Transformational Leadership (TRANS)}

Transformational leadership is defined as a leadership approach that causes change in individuals and organizations. Transformational leadership creates valuable and positive change in the followers with the end goal of developing followers into leaders [9]. Transactional leadership motivates followers by appealing to their self-interests and exchanging benefits. Transformational leadership behaviors are described in term of specific categories of behaviors. The taxonomy was identified primarily by factor analysis of behavior description questionnaire or called Multifactor leadership questionnaire (MLQ). The original 
formulation of theory [9] consisted of four types of behaviors and then one more transformational behavior was included in the other revised theories. In regards to transformational leadership, the five items - Idealized attributes, Idealized behaviors, Inspirational motivation, Intellectual stimulation, and Individualized consideration - are used in this study. Idealized attributes (TRANS1) are the characteristics of mutual respect between the leader and the followers. Idealized influence refers to leaders behaving as role models for their followers. The leaders are admired, respected, and trusted. Idealized behaviours (TRANS2): the reflective of the leader's observable actions, deeds, and conduct perceived by the follower. Idealized behaviours reference a leader who is highly trusted, has high moral and ethical principles, as well as exemplifies a strong sense of purpose. Inspirational Motivation (TRANS3): the degree to which the leader articulates a vision that is appealing and inspiring to followers. Leaders with inspirational motivation challenge followers with high standards, communicate optimism about future goals, and provide meaning for the task at hand. Followers need to have a strong sense of purpose if they are to be motivated to act. Intellectual Stimulation (TRANS4): the degree to which the leader challenges assumptions, takes risks and solicits followers' ideas. Leaders with this style stimulate and encourage creativity in their followers. They nurture and develop people who think independently. For such a leader, learning is a value and unexpected situations are seen as opportunities to learn. The followers ask questions, think deeply about things and figure out better ways to execute their tasks.

Individualized Consideration (TRANS5): the degree to which the leader attends to each follower's needs, acts as a mentor or coach to the follower and listens to the follower's concerns and needs. The leader gives empathy and support, keeps communication open and places challenges before the followers. This also encompasses the need for respect and celebrates the individual contribution that each follower can make to the team. The followers have a will and aspirations for self-development and have intrinsic motivation for their tasks.

\subsection{Psychological Empowerment (PSY)}

The importance to consider Psychological process is that participative practice and employee involvement program do not reduce the feeling powerlessness or leave people the feeling that their work is meaningful and worthwhile [10] for example, let co-worker determine how to do trivial tasks or unmeaning tasks is not likely to increase co-worker's feeling of self-worth or self-fulfillment. It is not empowered if delegating responsibility for meaningful tasks to co-workers who are lack of skills or knowledge required to perform successfully and is worried failure.

Theory of psychological empowerment is attempted to explain when and why efforts to empowered people are likely to be successful. According to [11], theories of psychological empowerment have been proposed by various scholar [10]. In this study, the following items [12] are adopted.

Self-efficacy (PSY1): the necessary ability and expertise to perform the job successfully; a sense of confidence in well accomplishment of the tasks

Self-determination (PSY2): the individual's feeling for optionality and being Initiative to regulate the activities, independence and continuity in the processes.

Self-regulation (PSY3) involves controlling one's behavior, emotions, and thoughts in the pursuit of long-term goals.

Personal acceptance of the consequence (PSY4): the extent of an individual's authority and influence on the strategic, administrative, or operational consequences of job activities.

Sense of meaningfulness (PSY5): the extent of occupational or job objectives value, the person is judged on personal ideals or standards.

\subsection{Employee Engagement (EE)}

Employee engagement has been defined in many ways. In the academic literature, a number of definitions of employee engagement have been provided. In this study, authors adopted the 
definition proposed by Schaufeli et al. [13], therefore, it is a concept that indicates the interaction, connection between individuals with each other or individuals with the organization. Many people believe that Employee Engagement is the level of employee satisfaction with the company. However, the engagement of employees with the company should be understood exactly as their passion, effort with work and organizational commitment. Four items of employee engagement were adopted in this study as follows:

Company (EE1): Employees feel personal attachment, affiliation, passion toward the company as a whole.

Job (EE2): Employees value and feel personal involvement with their work and the tasks associated with their specific jobs.

Supervisor/Leader (EE3): Employees feel personal attachment, commitment, and affiliation with their direct supervisors and higher level leaders.

Colleagues/co-workers (EE4): Employees value relationships and feel emotional attachment to the other members of their team or to colleagues that they work with directly.

\subsection{The Relationship of Transformational Leadership and Employee Engagement}

Transformational leadership is expected to raise followers to higher levels of potential while satisfying their higher - order needs and induce them to transcend their own self-interest for the sake of organization. Therefore, it is likely expected to increase employee dedication. Similarity, an employee who receives support, inspiration and quality coaching, advising from the supervisor, is likely to experience work as more challenging, involving and satisfying, and consequently, follower to become highly engaged with the jobs [14]. In addition, Avery, McKay, and Wilson [15] found that satisfaction with co-workers at working environment, it is significantly related to work's engagement of employees, while employees' feelings of involvement, cohesiveness, commitment, potency, and performance are enhanced by the transformational leadership style [14]. The study of Bakker et al., [14] showed that supervisor support, innovativeness, information, appreciation, and organizational climate can all be considered important job resources which particularly influences on work engagement. Saks [16] also showed findings that perceived organizational support predicts both job engagement and organization engagement, while transformational leader is likely played key influence on organization support to the follower, so transformational leadership is probably indirect enhancing job engagement of follower. Clearly, there are empirical evidences relationship between transformational leadership $\&$ follower engagement. Furthermore, there are some empirical studies was found the relationship as follow: Transformational leadership is positively associated with organizational commitment and work engagement. [4, 13]; Daily transformational leadership positively related to employees' daily engagement [14]; Empirical research from Hoper et al., [17] resulted significant positive relations between transformational leadership and work engagement; etc. Therefore, the following hypothesis is proposed:

H1: Transformational leadership has significant effect on Employee engagement.

\subsection{The Relationship of Transformational Leadership and Psychological Empowerment}

The behaviours, which generating from transformational leadership, transform their followers helping them to reach their full potential and generate the highest levels of performance. Through such means, transformational leadership is likely to generate a working environment help the followers feel empowered confident \& meaningful for seeking innovative approaches to perform successfully their job. A principal aspect of transformational leadership is its emphasis on follower development $[4,18]$. In addition, the theory has also consistently emphasized followers' 
development toward autonomy and empowerment over automatic followership [19]. Furthermore, Bass and Avolio [5] stated that transformational leaders enhance follower's capacity to think on their own \& develop new ideas; Avolio and Gibbons [20] posited that a major goal of transformational leaders is to develop follower self-management and selfdevelopment; Shamir (1991) similarly stressed the transformational effects of charismatic leaders on follower independence; Avolio and Gibbons [20] specified increased follower selfefficacy as a developmental effect of transformational leadership. Through such behaviours of transformational leadership, it is conceivable that influenced followers likely feel that they are intrinsically motivated by the leaders. Moreover, several studies [21, 22] emphasized that a leader can increase intrinsic motivation by increasing the perception of the followers that task objectives are consistent with their authentic interests and values and this perception is absolutely possible influenced by transformation behaviours. Indeed, there is empirical study found that the relationship between transformational leadership and psychological empowerment as mediating role of leadership outcomes [18, 23]. Based on the description above, the proposed hypothesis is as follows:

\section{H2: Transformational leadership has significant effect on Psychological empowerment.}

\subsection{The Relationship of Employees Engagement and Transformational Leadership with the Intervention of Psychological Empowerment}

According to earlier studies, work engagement is a positive, affective-motivational work-related state that is characterized by vigour, dedication, and absorption, while psychological empowerment emphasizes on instructs motivation and also define as a motivational concept composed of four dimensions: meaning, choice, competence and impact. Meaning corresponds to the value employees be assigned to their job according to their beliefs and standards. Impact refers to the degree that individual's work makes a difference in achieving the task goals and an individual believes he or she can influence organizational outcomes.

Although previous research has limitations, it was revealed that psychological empowerment is a significant predictor of work engagement. Autonomy, one of the core dimensions of empowerment, has been identified in recent meta-analyses and reviews to be a robust predictor of work engagement [24-26]. Self-efficacy, a construct similar to the competence dimension of empowerment, and meaningfulness has also been found to be associated with engagement [27]. Similarity, psychological empowerment is found that its direct influence on engagement in mediating role for influence of empowering leadership on engagement [28]. In an empirical research, Bakker et al. [14] found that daily transformational leadership related positively to employees' daily engagement through mediating role of Self-efficacy \& optimism; Quiñones et al. [29] stated that job resources may increase the perception of being empowered at work, which then represents an important factor to enhance work engagement. Psychological empowerment is thus a pathway to promote wellbeing in organizations. Finally, [30, 31] explored the links between psychological empowerment, work engagement, and innovation. It was found that psychological empowerment fostered work engagement, which then led to higher levels of innovation [29]. Hence, the proposed hypothesis is as follows:

\section{H3a: Psychological empowerment has significant effect on on Employee engagement.}

H3b: Transformational leadership has significant indirect effect on Employee engagement through the mediator Psychological empowerment.

Based on literature review and discussion above, the conceptual framework of this study is formulated by three main domains: Transformational leadership, Employee engagement and mediating role of Psychological empowerment in the relationship between Transformational leadership and Employee engagement. The proposed research framework is shown in Figure 1. 


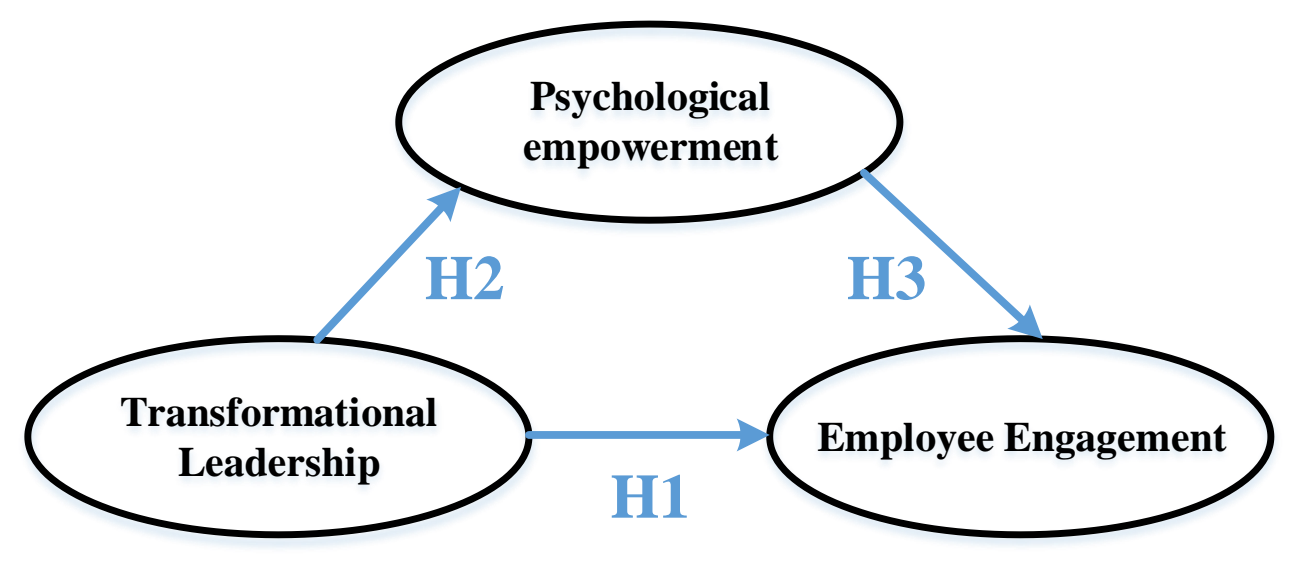

Figure 1. The research framework

\section{Research Methodology}

\subsection{Research Instrument}

The research questionnaire constructed for the purpose of this study was made up of the two sections. Section 1, including general and background information, covers the control variables of the survey by acquiring background data of the respondents and their organizations. Section 1 also outlines the purpose and objectives of the research and pertinent information relating to the rights and expectations of the respondents. Section 2 measured respondent's level of agreement (in a 5 point-scale) for 14 items. For the purpose of this study, only 14 items were utilised. The Transformational Leadership (TRANS) included five items, Psychological Empowerment (PSY) was a five-item instrument and Employee engagement (EE) was measured by four items. The scale was based on a 5-point Likert scale (1=strongly disagree, $2=$ disagree, $3=$ not sure, $4=$ agree, $5=$ strongly agree). Higher scores indicated higher levels.

\subsection{Data Collection}

The research was conducted with quantitative descriptive approach and the type of research empirical study supported by survey. The participants were recruited at random from various Vietnamese organizations. The nature of this research is explanatory research (explanatory research) is a study that aims to describe and explain the nature of an ongoing situation at the time of the study conducted and examined the causes of the symptoms. Primary data were collected through two primary tools: online and offline. For online tool, data collection was done through a questionnaire made available on the Google Forms platform. This enabled minimization of the costs on the part of the researcher and the company, and ease of reference and time convenience on the part of the management sample to which the survey was administered. A foreword of support for this study was sent out by the HR manager to endorse the research and encourage responses. The other method for data gathering is personal interview survey. An alternative for this method is that the participants were asked to complete a paper questionnaire. We stated the purpose of the questionnaire and assured the participants that their answers would remain confidential. Participants will be provided with a verbal overview about research objectives and information to ensure all the details of the project have been understood. All participants were informed of their right to withdraw from the study if they felt uncomfortable. The participants were told that they had the right to refuse to answer any particular question and no participants would be named in the publications, and every effort would be made to disguise their identity. At the end of questionnaire, the participants had the option to leave their e-mail address if they were 
interested in receiving a summary of the results. These steps fully guaranteed the rationality and integrity of data and meanwhile protected participants' privacy and rights.

Data collection was conducted between April 2019 to May 2019. A total of 351 questionnaires were issued to potential respondents in 18 companies. All participants were asked to complete two selfreported scales with good reliability and validity: Transformational Leadership (TRANS), Psychological Empowerment and Employee engagement (EE). Of the 301 survey questionnaires that were returned, only 254 were usable. The remaining seven were excluded from the data due to having been returned without being completed at all.

\subsection{Validity and Reliability Tests}

The data collected from the surveys were coded and entered into the SPSS statistical software for statistical calculation and analyses. The data collected was first checked for completeness and proper data entry prior to other analyses. The Cronbach's Alpha was used to measure the reliability of the instruments. The Cronbach's Alpha was utilized to measure the reliability of the instruments. the closer the reliability coefficient gets to 1.0 , the reliability is better. In general, reliability coefficient less than 0.60 are considered as poor, those in the range of 0.70 are acceptable and those above 0.80 are considered as good [32]. Then, the item-total correlation test was used to select items with an item-total correlation coefficient of .30 or higher. The items with low item-total correlations were removed.
To create a model that best fits the data, the confirmatory factor analysis (CFA), one of the techniques of structural equation modelling (SEM), were used. There are two types of factor analysis: exploratory and confirmatory. Exploratory factor analysis (EFA) is used to explore the underlying factor structure of a set of variables (possible relationships between variables), whereas CFA is based on prior knowledge or a conceptual foundation to confirm or reject hypothesized relationships [33]. Firstly, the EFA was used to explore the factorial structure and then the CFA was applied to confirm that. Given the complexity of structural equation modelling, it is necessary to identify whether the proposed model is good. Several CFA fit indices, including CMIN/df, CFI, GFI, TLI, RMR and RMSEA were adopted in this study.

\subsection{Path Analysis}

Path analysis is an extension of the multiple regression model that is used to evaluate causal models by examining the relationships between a dependent variable and two or more independent variables. A path analysis can be conducted as a hierarchical (sequential) multiple regression analysis. In a regression model, each Independent variable has direct on the dependent variable. In a path analysis model, in addition to direct effect there is also indirect effect of an independent variable, via a mediating variable, on the dependent variable.

\section{Results \\ Reliability and Validity Test}

Table 1. Reliability Test

\begin{tabular}{|c|c|c|c|c|}
\hline Variables & Items & $\begin{array}{l}\text { EFA loading } \\
\text { value }\end{array}$ & $\begin{array}{l}\text { Cronbach alpha } \\
\text { value }\end{array}$ & KMO \\
\hline \multirow[t]{5}{*}{ TRANS } & TRANS 2 & .857 & 0.875 & Kaiser-Meyer- \\
\hline & TRANS 3 & .853 & & Olkin $=.835$ \\
\hline & TRANS 4 & .788 & & Sig $=.000$ \\
\hline & TRANS 5 & .720 & & \\
\hline & TRANS 1 & .671 & & \\
\hline \multirow[t]{4}{*}{ PSY } & PSY 3 & .811 & 0.840 & \\
\hline & PSY 1 & .751 & & \\
\hline & PSY 2 & .734 & & \\
\hline & PSY 4 & .692 & & \\
\hline
\end{tabular}




\begin{tabular}{rlll}
\hline \multirow{2}{*}{ EE } & PSY 5 & .657 & \\
& EE 3 & .853 & 0.773 \\
EE 2 & .754 & \\
EE 1 & .738 & \\
EE 4 & .724 & all variables measurement has an acceptable level of \\
According to Table 1, with the obtained Cronbach & internal
\end{tabular}

Table 2. Model fit indicators

\begin{tabular}{ccc}
\hline Indicators & Criteria & Value by model \\
\hline$\chi^{2 / \mathrm{df}}$ & $<3$ & 2.522 \\
GFI & $>0.8$ & 0.977 \\
CFI & $>0.9$ & 0.988 \\
TLI & $>0.9$ & 0.923 \\
RMSEA & $\leq 0.08$ & 0.035 \\
\hline
\end{tabular}

Table 2 shows that the model are satisfactory. Specifically, GFI, CFI and TLI values are all above 0.9 . The root mean square error of approximation (RMSEA) has a value of 0.035 . This index is considered to be good if it is less than 0.08 . The goodness of fit result showed that the model fits the data quite well.

\section{Path analysis}

Table 3. Path analysis result

\begin{tabular}{lccccc}
\hline & \multicolumn{2}{c}{ Coefficient $(\boldsymbol{\beta})$} & & \\
\cline { 2 - 3 } \multicolumn{1}{c}{ Hypotheses } & Direct & Indirect & & Sig. & Result \\
\hline H1: TRANS $\rightarrow$ EE & .096 & - & & .039 & Supported \\
H2: TRANS $\rightarrow$ PSY & .433 & - & & .000 & Supported \\
H3a: PSY $\rightarrow$ EE & .192 & - & & .000 & Supported \\
H3b: TRANS $\rightarrow$ PSY $\rightarrow$ EE & - & .143 & & .000 & Supported \\
\hline
\end{tabular}

The result of multiple regression analysis showed that the Psychological Empowerment is significantly related with the two factors: Transformational leadership and Employee Engagement. Also from Table 3, it can be shown that there is a direct effect of Psychological Empowerment and Employee Engagement. Moreover, Transformational leadership not only has a direct impact on Employee Engagement, but also has indirect effect through Psychological Empowerment as a mediating variable. More specifically, the research results indicated that the direct impact of Psychological Empowerment is stronger than the direct impact of Transformational leadership on Employee engagement $(\beta=0.192$ and $\beta=0.096$ respectively). Transformational leadership also has the indirect effects on Employee Engagement $(\beta=0.143)$ via Psychological Empowerment. Thus, Psychological Empowerment plays the mediating role on the relationship between Transformational leadership and Psychological Empowerment.

\section{Conclusions and Discussions}

In today's increasingly dynamic work environment, employees always expect certain autonomy in their work place. Therefore, accordingly to the research results, it is indicated that Psychological empowerment has played a significant role as an intermediate variable between Transformational leadership and Employee Engagement components.

In an economy where external factors can change at any time, one of the measures to ensure a company's sustainable competitiveness and increase its success rate is to focus on its employees. Business leaders are often advised not to become micromanagement, i.e. not to interfere deeply with the day-to-day operations of their employees and to demonstrate this by putting trust in their employees, or empowering to help them make their own 
decisions. In addition to the essential soft skills of talented leaders, a good way for good leaders to empower their employees is also essential.

As a role of transformational leadership, leaders should always move towards of putting people at the centre of all activities. Trusting and empowering employees leading to leaders will have plenty of time to focus on long-term plans and strategies for the company. The empowered person will face many challenges but also feel his ability which is trusted by the leader that creates conditions for employees to practice independence, self-determination of work within the rights. Therefore, transformational leadership increases the sense of responsibility of the team and also encourages employees to be creative and inspiring at work, so that the responsibility in the work will be improved. At the same time, empowerment also increases the level of engagement of employee.

The most important factor when giving employees the right to self-determination is to have a rigorous way to associate their responsibilities with the overall results and goals of the business. The mission of the business in this situation is to establish a long-term development strategy, while providing a specific working and development context for the employees. Strategies affecting the overall goals of the organization must be highly practical, need to be measured and continually responded to minimize unnecessary risks. Staff and teams working at this time should be aware of their rights and responsibilities. The freedom and autonomy they gain must adhere to the picture the company is aiming for. All activities that benefit the common goal that the organization is pursuing will be fully supported to develop. On the contrary, excessive freedom that damages the growth flywheel will have to be removed immediately.

Limitation of this study is using cross-section design and convenience sampling. In addition, companies in remote areas of Vietnam were not including in the target samples because of unreachability; consequently, research findings may not be generalized for the entire Vietnamese organizations. For future research, generalizability of results and practical implications should be examined in other areas in Vietnam and in different types of organizations.

\section{References:}

[1] Pieterse-Landman E (2012) The relationship between transformational leadership, employee engagement, job characteristics and intention to quit

[2] Hatch NW, Dyer JH (2004) Human capital and learning as a source of sustainable competitive advantage. Strateg Manag J 25:1155-1178.

[3] Hayati D, Charkhabi M, Naami AZ (2014) The relationship between transformational leadership and work engagement in governmental hospitals nurses: A survey study. Springerplus 3:1-7.

[4] Avolio BJ, Zhu W, Koh W, Bhatia P (2004) Transformational leadership and organizational commitment: Mediating role of psychological empowerment and moderating role of structural distance. J Organ Behav Int J Ind Occup Organ Psychol Behav 25:951-968

[5] Bass BM, Avolio BJ (1990) Developing transformational leadership: 1992 and beyond. J Eur Ind Train 14:

[6] Meng Q, Sun F (2019) The impact of psychological empowerment on work engagement among university faculty members in China. Psychol Res Behav Manag 12:983. https://doi.org/10.2147/PRBM.S215912

[7] Lightfoot SL (1986) On goodness in schools: Themes of empowerment. Peabody J Educ 63:9-28

[8] Seibert SE, Wang G, Courtright SH (2011) Antecedents and Consequences of Psychological and Team Empowerment in Organizations: A Meta-Analytic Review. J Appl Psychol 96:981. https://doi.org/10.1037/a0022676

[9] Bass BM, Bass Bernard M (1985) Leadership and performance beyond expectations

[10] Conger JA, Kanungo RN, Menon ST, Mathur P (2009) Measuring Charisma: Dimensionality and Validity of the CongerKanungo Scale of Charismatic Leadership. Can J Adm Sci / Rev Can des Sci l'Administration 14:290-301. https://doi.org/10.1111/j.19364490.1997.tb00136.x

[11] Gary Y (2005) Leadership in Organization; five edition. alih Bhs Budi Supriyanto), Jakarta PT Indeks

[12] Spreitzer GM (1995) Psychological empowerment in the workplace: Dimensions, measurement, and validation. Acad Manag J 38:1442-1465

[13] Schaufeli W, Salanova M, González-romá V, Bakker A (2002) The Measurement of Engagement and Burnout: A Two Sample Confirmatory Factor Analytic Approach. J 
Happiness Stud 3:79-92.

[14] Bakker AB, Hakanen JJ, Demerouti E, Xanthopoulou D (2007) Job resources boost work engagement, particularly when job demands are high. J Educ Psychol 99:274.

[15] Avery DR, McKay PF, Wilson DC (2007) Engaging the Aging Workforce: The Relationship Between Perceived Age Similarity, Satisfaction With Coworkers, and Employee Engagement. J Appl Psychol 92:1542.

[16] Saks AM (2006) Antecedents and consequences of employee engagement. J Manag Psychol 21:600-619

[17] Vincent- Höper S, Muser C, Janneck M (2012) Transformational leadership, work engagement, and occupational success. Career Dev Int 17:663-682

[18] Avolio BJ, Locke EE (2002) Contrasting different philosophies of leader motivation: Altruism versus egoism. Leadersh Q 13:169191

[19] Graham JW (1988) Transformational leadership: Fostering follower autonomy, not automatic followership. Emerg Leadersh vistas 25:73-79

[20] Avolio BJ, Gibbons TC (1988) Developing transformational leaders: A life span approach.

[21] Bono JE, Judge TA (2003) Self-concordance at work: Toward understanding the motivational effects of transformational leaders. Acad Manag J 46:554-571

[22] Charbonneau D, Barling J, Kelloway EK (2001) Transformational leadership and sports performance: The mediating role of intrinsic motivation 1. J Appl Soc Psychol 31:1521-1534

[23] Jung DI, Chow C, Wu A (2003) The role of transformational leadership in enhancing organizational innovation: Hypotheses and some preliminary findings. Leadersh Q 14:525-544.

[24] Halbesleben JRB (2010) A meta-analysis of work engagement: Relationships with burnout, demands, resources, and consequences. Work Engagem A Handb Essent theory Res 8:102-117

[25] Mauno S, Ruokolainen M, Kinnunen U, De Bloom J (2016) Emotional labour and work engagement among nurses: examining perceived compassion, leadership and work ethic as stress buffers. J Adv Nurs 72:11691181

[26] Mauno S, Kinnunen U, Ruokolainen M (2007) Job demands and resources as antecedents of work engagement: A longitudinal study. J Vocat Behav 70:149171

[27] May DR, Gilson RL, Harter LM (2004) The psychological conditions of meaningfulness, safety and availability and the engagement of the human spirit at work. J Occup Organ Psychol 77:11-37

[28] Albrecht SL, Andreetta M (2011) The influence of empowering leadership, empowerment and engagement on affective commitment and turnover intentions in community health service workers. Leadersh Heal Serv 24:228-237

[29] Quiñones M, Van den Broeck A, De Witte H (2013) Do job resources affect work engagement via psychological empowerment? A mediation analysis. Rev Psicol del Trab y las Organ 29:127-134

[30] Bhatnagar J (2012) Management of innovation: Role of psychological empowerment, work engagement and turnover intention in the Indian context. Int $\mathrm{J}$ Hum Resour Manag 23:928-951

[31] Bhatnagar J, Biswas S (2012) The mediator analysis of psychological contract: relationship with employee engagement and organisational commitment. Int J Indian Cult Bus Manag 5:644-666

[32] Sekaran U (2003) Research Methods for Business: A skill-bulding approach. New York: John Willey and Son. Inc Year

[33] Hair JF, Anderson RE, Babin BJ, Black WC (2010) Multivariate data analysis: A global perspective (Vol. 7)

Creative Commons Attribution License 4.0 (Attribution 4.0 International, CC BY 4.0)

This article is published under the terms of the Creative Commons Attribution License 4.0

https://creativecommons.org/licenses/by/4.0/deed.en_US 